\title{
Performance of activities in daily living in children born with spina
} bifida

\author{
Marie Peny-Dahlstrand*1, Anne-Christine Åhlander ${ }^{1}$, \\ Lena Krumlinde Sundholm² and Gunilla Gosman-Hedström³
}

\author{
Address: ${ }^{1}$ Queen Silvia's Children and Adolescents Hospital, 41804 Gothenburg, Sweden, ${ }^{2}$ Department of Woman and Child health, Karolinska \\ Institute, Astrid Lindgrens Children's hospital 17176 Stockholm, Sweden and 3Sahlgenska Academy, University of Gothenburg, Institute for \\ Neuroscience and Physiology. 40530 Gothenburg, Sweden \\ Email: Marie Peny-Dahlstrand* - marie.peny-dahlstrand@vgregion.se \\ * Corresponding author
}

from 52nd Annual Meeting of the Society for Research into Hydrocephalus and Spina Bifida Providence, RI, USA. II-I4 June 2008

Published: 3 February 2009

Cerebrospinal Fluid Research 2009, 6(SuppI I):SI7 doi:I0.II86/I743-8454-6-SI-SI7

This abstract is available from: http://www.cerebrospinalfluidresearch.com/content/6/SI/SI7

(c) 2009 Peny-Dahlstrand et al; licensee BioMed Central Ltd.

\section{Background}

Dependency in daily living in children with spina bifida has most commonly been described as a problem due to motor dysfunctions and little is known about the impact on the performance of daily living activities due to executive dysfunction. The aim of this study was to evaluate the quality of the performance of daily activities in children with spina bifida.

\section{Materials and methods}

A cross-sectional study of children from the western region of Sweden with spina bifida $(\mathrm{n}=50)$ born between 1993-1999, was carried out at the Regional Rehabilitation Centre for children and adolescents in Gothenburg to evaluate performance of activities in daily living using the Assessment of Motor and Process Skills (AMPS). The study group consisted of both children with and without hydrocephalus. The AMPS is an observational method designed to allow a simultaneous evaluation of the motor and process skills necessary for a competent performance. The results from the study group were analysed and compared to age-matched normative values and to matchpairs of typically developed Scandinavian children, in the latter case considering minimal clinical important differences ( $>0,5$ logits).

\section{Results}

The results showed that $60 \%$ of the children with spina bifida had lower ADL-motor skills and $48 \%$ had lower ADL-process skills than the age norms $( \pm 2 \mathrm{SD})$. Results from the match-pair comparisons shows that the study group had skill values that were lower and of clinical meaningful importance on motor skills in $80 \%$ of the cases and on process skills in $66 \%$ of the cases. There were significant differences in both motor skills and process skills in the study group between the children with and those without hydrocephalus with the former group demonstrating lower measures.

\section{Conclusion}

Children with spina bifida have, to a large extent, decreased ability to perform activities of daily living relating to impairment of both motor and process abilities. These findings suggests that to reach autonomy in daily life, children born with spina bifida need support from parents and professionals to find, to learn and to use strategies not only to know "how to do things" but also "how to get things done". 